\title{
Synergistic Degradation of 4-Nitrophenol Using Hydrodynamic Cavitation in Combination with Hydrogen Peroxide
}

\author{
Mihir N. Bhagat, Mandar P. Badve, and Aniruddha B. Pandit* \\ Department of Chemical Engineering, Institute of Chemical Technology, Mumbai, India
}

\begin{abstract}
p-Nitrophenol (PNP), a widely utilized intermediate, is a persistent pollutant present in industrial effluent streams. The inherent toxicity of PNP necessitates its treatment before releasing it in the environment. The conventional approach pertaining to degradation of PNP is based on chemical and biological methods for decomposition. Alternatively, Hydrodynamic Cavitation (HC) is emerging as a promising technology for waste water treatment. This study investigates $\mathrm{HC}$ as an alternative technology to degrade PNP and subsequently enhance efficiency by varying involved parameters. The HC-H2O2 system is reported to exhibit synergism for pollutant oxidation, the applicability of which is also investigated for degrading PNP. A PNP solution of fixed concentration was subjected to HC using a circular Venturi. Degradation was studied by varying time, pressure, $\mathrm{pH}$ and $\mathrm{H} 2 \mathrm{O} 2$ concentration. Decompostion of $\mathrm{p}$ Nitrophenol was quantified by UV-Visible Spectroscopy at $405 \mathrm{~nm}$. Degradation of PNP was observed to be directly proportional to time at constant pressure and an initial increase in pressure led to higher degradation. However, on achieving a peak decomposition level, the extent of decomposition declined with further increase in pressure. Experiments done at acidic $\mathrm{pH}$ resulted in over two times the decomposition than those done at basic $\mathrm{pH}$. The PNP$\mathrm{H} 2 \mathrm{O} 2$ system exhibited $91 \%$ more degradation than the sum of degradations affected by PNP and $\mathrm{H} 2 \mathrm{O} 2$ individually. Moreover, subjecting PNP:H2O2 in a molar ratio of 1:5 to HC resulted in near-complete (>95\%) degradation. This study proposes variations of parameters for optimum decomposition of PNP using $\mathrm{HC}$ and explores the $\mathrm{HC}-\mathrm{H} 2 \mathrm{O} 2$ system as a promising alternative for the degradation PNP.
\end{abstract}

Keywords: p-Nitrophenol, Hydrodynamic Cavitation, Synergism, Wastewater Treatment.

\section{Introduction}

p-Nitrophenol (PNP) is an important intermediate for the manufacture of dyes, pigments, pesticides (Parathion and Fluoridifen), explosives, engineering polymers and pharmaceuticals (Acetaminophen) [1],[2],[3]. Such widespread usage of PNP generates enormous quantities of PNP-laden industrial and agricultural effluents which do not degrade easily and persist in the environment for a long time [4]. Moreover, PNP is a priority pollutant as classified by the US EPA and is severely toxic having a LD50 value of $667 \mathrm{mg} / \mathrm{kg}$ (Rat, Oral) and a LC50 value of $5.8 \mathrm{mg} / \mathrm{L}$ (fish)[5]. It thus becomes imperative to treat PNP-laden effluents before discharging them in the environment.

${ }^{*}$ Corresponding author

E-mail: ab.pandit@ictmumbai.edu.in

(C) 2015 International Association for Sharing Knowledge and Sustainability

DOI: $10.5383 /$ swes.7.01.008
Substantial amount of work has been conducted on PNP degradation using photocatalysts. San et al[6] have attempted degradation of PNP using a TiO2 catalyst in presence of UV light and achieved 58.7\% PNP degradation over $160 \mathrm{~min}$ of irradiation. Paola et al [7] have gone a step further and performed PNP degradation with a TiO2+Mo loaded catalyst under UV light. Their experiments exhibited quantitative PNP degradation after $150 \mathrm{~min}$. of treatment while using a TiO2-HP catalyst.

Bhatti et al [3] have quantitatively degraded PNP using an activated sludge for a hydraulic retention time of $11 \mathrm{~h}$ when using fresh sludge. Jain et al[8] have also performed a 
biodegradation on PNP using an Arthrobacter Sp. strain, achieving complete degradation to give products such as 1,2,4benzenetriol and Hydroquinone. However, all such methods require high processing times to obtain sufficient degradation.

Hydrodynamic Cavitation (HC) is an emerging technology for the effluent treatment. It utilizes the phenomena of formation, growth and implosion of bubbles to release concentrated amounts of energy [9] and generate reactive radicals such as $\mathrm{H}^{\bullet}$ and $\bullet \mathrm{OH}$, which bring about chemical reactions [10], microbial cell disruption [11] and effluent treatment [12]. Capocelli et al [13] have studied the degradation of PNP via HC at various cavitation conditions to obtain modest yields. Though a faster technology, $\mathrm{HC}$ as a stand-alone process is unable to match efficiencies exhibited by conventional processes.

Hydrogen peroxide is a well-known oxidizing agent for treating persistent pollutants and microbial cells [14], [15]. It is known to synergistically enhance efficiencies of $\mathrm{HC}$ treatments, to great effect [16]. Pradhan et al [17] have utilized Fenton Chemistry to degrade PNP using $\mathrm{Fe}+2 / \mathrm{H} 2 \mathrm{O} 2$ along with $\mathrm{HC}$ to great effect, achieving maximum PNP removal of $63.2 \%$. The following work attempts to build upon this synergism between $\mathrm{HC}$ and $\mathrm{H} 2 \mathrm{O} 2$ to achieve higher PNP degradation extents.

\section{Materials and Methods}

\subsection{Materials}

Laboratory grade 4-Nitrophenol was procured from Thomas Baker (Chemicals) Pvt. Ltd. and diluted using distilled water for conducting experiments. Reagent grade Sodium hydroxide pellets and Sodium thiosulfate were purchased from High Media Pvt. Ltd. Other chemicals such $98 \%$ sulfuric acid and $30 \% \mathrm{v} / \mathrm{v}$ Hydrogen peroxide were also obtained from Thomas Baker (Chemicals) Pvt. Ltd.

\subsection{Hydrodynamic Cavitation Setup}

$\mathrm{HC}$ was performed in a stainless steel setup as utilized by Badve et al [18], and described in Fig. 1. The setup consists of a holding tank, a 3-phase variable frequency drive (VFD)connected positive displacement pump, a main line (connects the cavitation device) and a bypass line, all being interconnected with pipes and valves. A pipe connecting the bottom of the holding tank transfers fluid to the pump which in turn discharges fluid to a main line, via the cavitation device or to a bypass line. Both the main and bypass lines terminate in the tank. Care is taken to avoid inducing air in the fluid by ensuring discharge below the liquid level in the tank.

A circular venturi was used as the cavitation device as described by Badve et al [18], having the following dimensions:

Table 1. Dimensions of Circular Venturi Used for HC

\begin{tabular}{lc}
\hline \multicolumn{1}{c}{ Dimension } & Value \\
\hline Throat & $2 \mathrm{~mm}$ diameter \\
\hline Total length & $106 \mathrm{~mm}$ \\
\hline Length of convergent section & $18 \mathrm{~mm}$ \\
\hline Length of divergent section & $67 \mathrm{~mm}$ \\
\hline Half angle of convergent section & $22.6^{\circ}$ \\
\hline Half angle of divergent section & $6.5^{\circ}$ \\
\hline
\end{tabular}

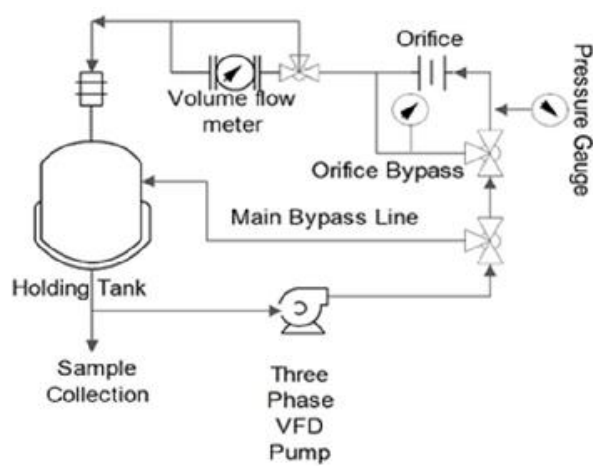

Fig. 1. HC Setup Schematic Diagram

\subsection{Experimental Methods}

All experiments were carried out using $5 \mathrm{~L}$ of a $10 \mathrm{ppm} 4-$ Nitrophenol solution at $30^{\circ} \mathrm{C}$. This solution was subjected to $\mathrm{HC}$ treatment using the venturi for parameters such as pressure, $\mathrm{pH}$ and $\mathrm{H}_{2} \mathrm{O}_{2}$ concentration. $50 \mathrm{~mL}$ samples were withdrawn at regular intervals of time for all experiments. Samples for experiments conducted in presence of $\mathrm{H}_{2} \mathrm{O}_{2}$ were quenched with $\mathrm{Na}_{2} \mathrm{~S}_{2} \mathrm{O}_{3}$ after collection to neutralize unreacted $\mathrm{H}_{2} \mathrm{O}_{2}$. Samples were then diluted three times using distilled water and analyzed using UV-Visible spectroscopy at $405 \mathrm{~nm}$ at neutral $\mathrm{pH}[19]$. The absorbances of samples were compared with a standard concentration-absorbance curve for 4-nitrophenol to obtain concentrations of PNP after degradation.

\section{Results and Discussion}

\subsection{Effect of operating pressure on PNP degradation}

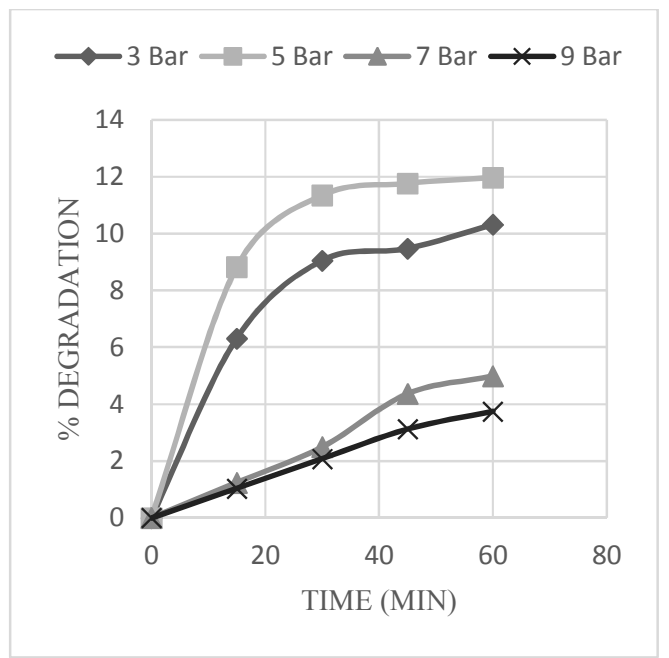

Fig. 2. Effect of Inlet Pressure on PNP Degradation

Fig. 2 describes the percentage of PNP degraded versus time, at various operating pressures. It is observed that degradation increases with pressure up to an optimum, following which it follows a decreasing pattern. It is also noted that most of possible degradation occurs within 30 minutes of treatment. 
Badve et al [18]have attributed this behavior to the Cavitation number, defined as:

$$
C_{v}=\frac{\left(p_{2}-p_{v}\right)}{(1 / 2) \rho v_{o}^{2}}
$$

Where $C_{v}$ is the cavitation number, $P_{v}$ is the vapor pressure of the fluid, $\mathrm{P}_{2}$ is the inlet pressure, $\rho$ is the fluid density and $\mathrm{v}_{\mathrm{o}}$ is the velocity of the liquid at the constriction. Cavitation ideally occurs for $\mathrm{Cv} \leq[20]$. Thus, as the pressure initially increased in our study, the velocity at the constriction increases, resulting in higher cavitation. However, after 5 Bar pressure, the number of cavities generated is so high that they begin coalescing, leading to lower degradation levels.

5 Bar of inlet pressure was found to display optimum PNP degradation and was fixed for subsequent experiments.

\subsection{Effect of Solution pH on PNP Degradation}

Fig. 3 depicts PNP degradation over time at different $\mathrm{pH}$ values for $5 \mathrm{Bar}$ inlet pressure. It is noticed that degradation is higher at lower $\mathrm{pH}$ and subsequently decreases on increasing $\mathrm{pH}$. Capocelli et al[13], infer that at a $\mathrm{pH}$ higher than its $\mathrm{pKa}$ of 7.15 , PNP exists in its phenoxide form. This phenoxide form faces electrostatic repulsion away from cavities, resulting in lower degradation. They further report that ${ }^{\circ} \mathrm{OH}$ radicals generated as a result of $\mathrm{HC}$, show reduced recombination abilities in acidic media and are thus more potent as oxidants. The degradation at $\mathrm{pH} 8$ is similar to that at $\mathrm{pH} 10$ which indicates that degradation could is of $\mathrm{pH}$ in once the phenoxide formation occurs.

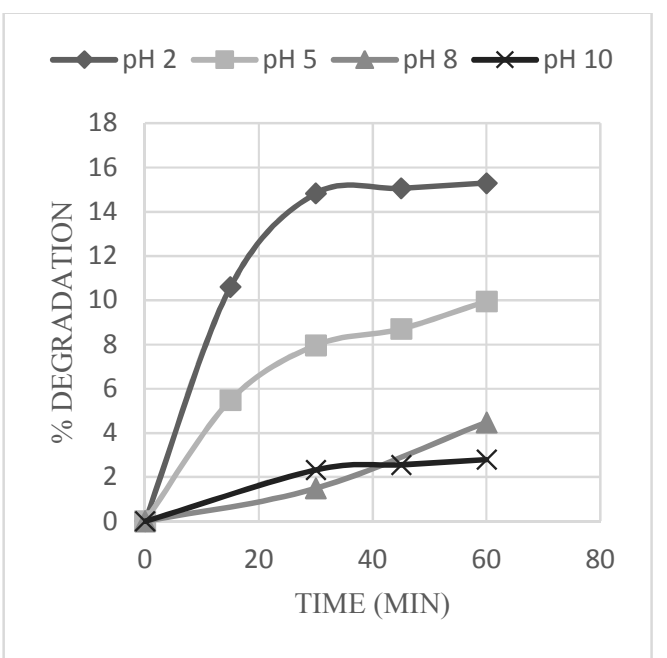

Fig. 3. Effect of Solution Ph on PNP Degradation at 5 Bar Pressure

\subsection{Effect of $\mathrm{H}_{2} \mathrm{O}_{2}$ concentration on PNP degradation}

$\mathrm{H}_{2} \mathrm{O}_{2}$ is a well-known reagent for treating organic contaminants such as PNP via ${ }^{\circ} \mathrm{OH}$ radical attack[18]. However, slow rates of $\bullet \mathrm{OH}$ generation in dilute media require high concentrations of $\mathrm{H}_{2} \mathrm{O}_{2}$ to effect substantial degradation on PNP. HC is known to address this issue by enhancing ${ }^{\circ} \mathrm{OH}$ generation, as mentioned by Raut-Jadhav et al[21]. We utilized $\mathrm{H}_{2} \mathrm{O}_{2}$ in lower concentrations to generate such radicals using $\mathrm{HC}$ for PNP degradation. Fig. 4 describes the extent of PNP degradation using $\mathrm{HC}$ in presence of varying concentrations of $\mathrm{H}_{2} \mathrm{O}_{2}$, at 5 Bar pressure. A further increase in $\mathrm{H}_{2} \mathrm{O}_{2}$ concentration directly results in higher PNP degradation until a molar ratio of 1:5, at

which the optimum degradation of $95 \%$ is reported. Higher concentrations reporting no further increase in degradation suggests a saturation of $\bullet \mathrm{OH}$ radicals.

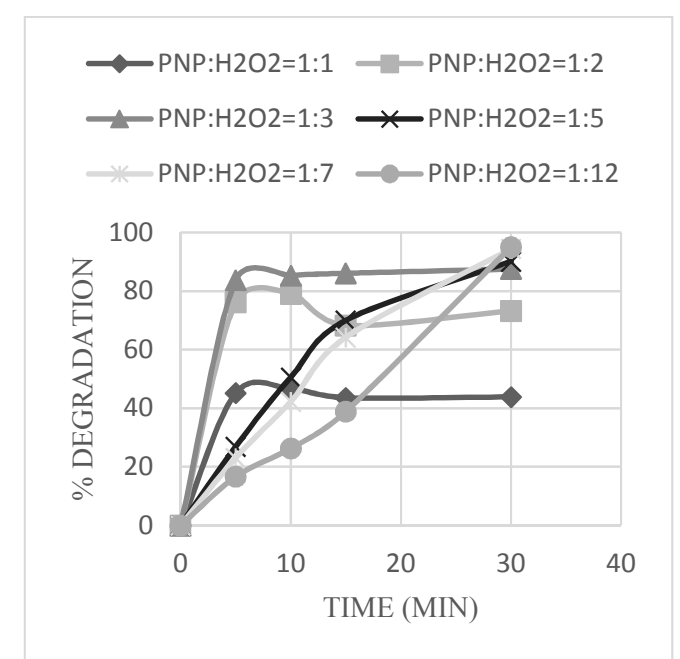

Fig. 4. Effect of PNP: $\mathrm{H}_{2} \mathrm{O}_{2}$ Molar Ratio on PNP Degradation

\section{Synergism between $\mathrm{HC}$ and $\mathrm{H}_{2} \mathrm{O}_{2}$}

In order to explore the synergism between $\mathrm{H}_{2} \mathrm{O}_{2}$ and $\mathrm{HC}$ for PNP degradation, three experiments were conducted as depicted in Fig. 5. The effect of $\mathrm{H}_{2} \mathrm{O}_{2}$ on PNP alone was studied by stirring a mixture of PNP and $\mathrm{H}_{2} \mathrm{O}_{2}$ in $1: 1$ molar ratio over $30 \mathrm{~min}$. Contributions arising solely due to cavitation were analyzed by $\mathrm{HC}$ treatment at 5 Bar pressure to the PNP solution. Finally, the synergism between $\mathrm{H}_{2} \mathrm{O}_{2}$ and $\mathrm{HC}$ was studied by subjecting a mixture of PNP and $\mathrm{H}_{2} \mathrm{O}_{2}$ in 1:1 molar ratio to $\mathrm{HC}$.

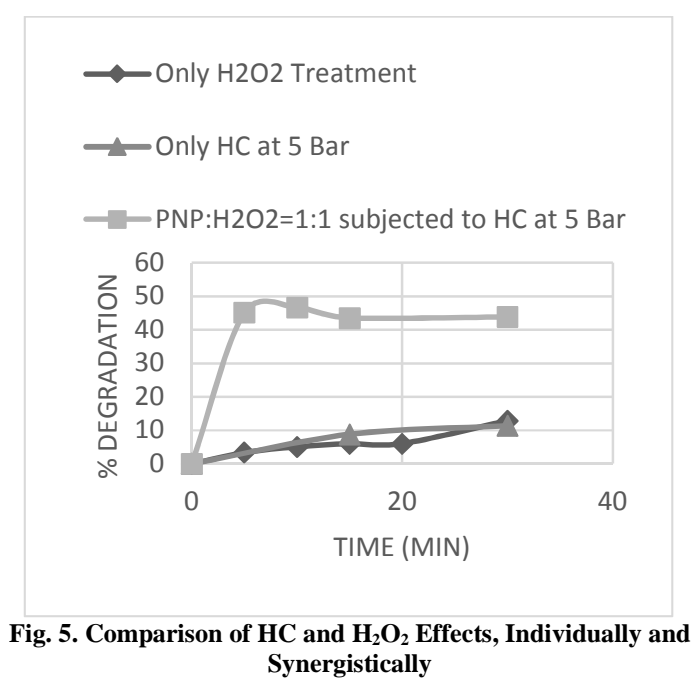

On analysis it was found that PNP degradation for the synergistic system was $44 \%$ and $11 \%, 12 \%$ respectively for $\mathrm{HC}$ and $\mathrm{H}_{2} \mathrm{O}_{2}$ being used exclusively. This represents $91 \%$ increase over the sum of degradation levels observed for individual parameters. It is also noted that all of the degradation in the 
synergistic system occurs within $5 \mathrm{~min}$ of treatment time, significantly reducing PNP effluent treatment times. A reasoning for this behavior could be derived from the fact that a substantial amount of degradation using $\mathrm{HC}$ is effected by hydroxyl radicals generated during cavity implosions. Similarly, Hydrogen peroxide on being subjected to $\mathrm{HC}$, rapidly undergoes homolytic cleavage produce two hydroxyl radicals. This supply of hydroxyl radicals makes good contact with PNP molecules due to efficient mixing during HC. This behavior is a likely reason for the $91 \%$ rise in efficiency of $\mathrm{PNP}$ by $\mathrm{HC}$ in presence of $\mathrm{H}_{2} \mathrm{O}_{2}$.

\section{Conclusion}

Hydrodynamic cavitation was utilized to study the degradation of 4-Nitrophenol. It was observed that increasing pressure increased PNP degradation upto an optimum level after which it declined. Acidic $\mathrm{pH}$ favored higher degradation of PNP over basic $\mathrm{pH}$. However, pressure and $\mathrm{pH}$ variations did not sufficiently degrade PNP to acceptable levels in short times. Hydrogen peroxide, known to exhibit synergism with $\mathrm{HC}$, was combined with $\mathrm{HC}$ to study the degradation of PNP. In this case, degradation levels were $91 \%$ more than the additive degradations exhibited by $\mathrm{HC}$ and $\mathrm{H}_{2} \mathrm{O}_{2}$ alone. Subjecting a mixture of $1: 5 \mathrm{~mol} / \mathrm{mol} \mathrm{PNP}: \mathrm{H}_{2} \mathrm{O}_{2}$ to $\mathrm{HC}$ effected $95 \%$ degradation over $30 \mathrm{~min}$ of treatment. Such results propose the $\mathrm{HC}-\mathrm{H}_{2} \mathrm{O}_{2}$ system as an alternative to conventional treatment processes for PNP.

\section{Future Scope}

Further work can include identification of intermediates to propose a PNP degradation mechanism. Other parameters such as heat treatment, alternative cavity designs, other oxidizing agents $\left(\mathrm{Cl}_{2}, \mathrm{NaClO}, \mathrm{O}_{3}\right.$, etc) could be varied to enhance efficiencies, treatment times and costs. Not only does applicability of the $\mathrm{HC}-\mathrm{H}_{2} \mathrm{O}_{2}$ synergy for degrading other such pollutants holds promise but other such oxidants to be used in conjunction with $\mathrm{HC}$ must be investigated upon.

\section{Acknowledgments}

Mihir Bhagat would like to express gratitude towards Department of Chemical Engineering, Institute of Chemical Technology, Mumbai for providing research facilities and financial assistance for the project.

\section{References}

[1] E. Lipczynska Kochany, "Novel method for a photocatalytic degradation of 4 nitrophenol in homogeneous aqeuous solution," Environ. Technol., vol. 12, no. 1, pp. 87-92, 1991.

[2] M. S. Dieckmann and K. a. Gray, "A comparison of the degradation of 4-nitrophenol via direct and sensitized photocatalysis in $\mathrm{TiO} 2$ slurries," Water Res., vol. 30, no. 5, pp. 1169-1183, 1996.

[3] Z. I. Bhatti, H. Toda, and K. Furukawa, "p-Nitrophenol degradation by activated sludge attached on nonwovens," Water Res., vol. 36, no. 5, pp. 1135-1142, 2002.

[4] Agency for Toxic Substances and Disease Registry, "Toxicological profile for nitrophenols: 2-nitrophenol, 4nitrophenol," 1992.

[5] "Test Plan for 4-Nitrophenol, High Production Volume Chemicals Challenge Program, US EPA,” 2004.
[6] N. San, A. Hatipoğlu, G. Koçtürk, and Z. Çınar, "Photocatalytic degradation of 4-nitrophenol in aqueous TiO2 suspensions: Theoretical prediction of the intermediates," $J$. Photochem. Photobiol. A Chem., vol. 146, no. 3, pp. 189 197, 2002.

[7] a. Di Paola, G. Marcì, L. Palmisano, M. Schiavello, K. Uosaki, S. Ikeda, and B. Ohtani, "Preparation of polycrystalline Tio2 photocatalysts impregnated with various transition metal ions: Characterization and photocatalytic activity for the degradation of 4-nitrophenol," J. Phys. Chem. $B$, vol. 106, no. 3, pp. 637-645, 2002.

[8] R. K. Jain, J. H. Dreisbach, and J. C. Spain, "Biodegradation of p-nitrophenol via 1, 2, 4-benzenetriol by an Arthrobacter sp.," Appl. Environ. Microbiol., vol. 60, no. 8, pp. 30303032, 1994.

[9] K. S. Suslick, M. M. Mdleleni, and J. T. Ries, "Chemistry induced by hydrodynamic cavitation," J. Am. Chem. Soc., vol. 119, no. 39, pp. 9303-9304, 1997.

[10] J. Ji, J. Wang, Y. Li, Y. Yu, and Z. Xu, "Preparation of biodiesel with the help of ultrasonic and hydrodynamic cavitation," Ultrasonics, vol. 44, no. SUPPL., 2006.

[11] S. S. Save, A. B. Pandit, and J. B. Joshi, "Scale Microbial Cell Disruption," IChemE, vol. 75 , no. Part C, pp. 4-12, 1997.

[12] A. G. Chakinala, P. R. Gogate, A. E. Burgess, and D. H. Bremner, "Industrial wastewater treatment using hydrodynamic cavitation and heterogeneous advanced Fenton processing," Chem. Eng. J., vol. 152, no. 2-3, pp. 498-502, 2009.

[13] M. Capocelli, M. Prisciandaro, A. Lancia, and D. Musmarra, "Hydrodynamic cavitation of p-nitrophenol: A theoretical and experimental insight," Chem. Eng. J., vol. 254, pp. 1-8, Oct. 2014.

[14] M. Wagner, D. Brumelis, and R. Gehr, "Disinfection of wastewater by hydrogen peroxide or peracetic acid: development of procedures for measurement of residual disinfectant and application to a physicochemically treated municipal effluent.," Water Environ. Res., vol. 74, no. 1, pp. $33-50,2014$

[15] N. H. Ince, "Critical effect of hydrogen peroxide in photochemical dye degradation," Water Res., vol. 33, no. 4, pp. 1080-1084, 1999.

[16] F. I. Ahmed and C. Russell, "Synergism between ultrasonic waves and hydrogen peroxide in the killing of microorganisms.," J. Appl. Bacteriol., vol. 39, no. 1, pp. 31-40, 1975.

[17] A. a. Pradhan and P. R. Gogate, "Removal of p-nitrophenol using hydrodynamic cavitation and Fenton chemistry at pilot scale operation," Chem. Eng. J., vol. 156, no. 1, pp. 77-82, Jan. 2010.

[18] M. P. Badve, M. N. Bhagat, and A. B. Pandit, "Microbial disinfection of seawater using hydrodynamic cavitation," Sep. Purif. Technol., vol. 151, pp. 31-38, 2015.

[19] a. Bibby and L. Mercier, "Adsorption and separation of water-soluble aromatic molecules by cyclodextrinfunctionalized mesoporous silicaElectronic supplementary information (ESI) available: Figs. S1-5: distribution coefficient profiles. See http://www.rsc.org/suppdata/gc/b2/b20925," Green Chem., vol. 5, no. 1, pp. 15-19, 2002.

[20] V. K. Saharan, M. P. Badve, and A. B. Pandit, "Degradation of Reactive Red 120 dye using hydrodynamic cavitation," Chem. Eng. J., vol. 178, pp. 100-107, 2011.

[21] S. Raut-Jadhav, V. K. Saharan, D. Pinjari, S. Sonawane, D. Saini, and A. Pandit, "Synergetic effect of combination of AOP's (hydrodynamic cavitation and $\mathrm{H}_{2} \mathrm{O}_{2}$ ) on the degradation of neonicotinoid class of insecticide," J. Hazard. Mater., vol. 261, pp. 139-147, 2013. 